\title{
Dechlorination of trichloroethylene in aqueous solution by noble metal-modified iron
}

\author{
Chin Jung Lin*, Shang Lien Lo, Ya Hsuan Liou \\ Graduate Institute of Environmental Engineering, National Taiwan University, 71 Chou-Shan Road, Taipei 106, Taiwan
}

Received 6 June 2004; received in revised form 7 September 2004; accepted 8 September 2004

Available online 22 October 2004

\begin{abstract}
Bimetallic particles are extremely interesting in accelerating the dechlorination of chlorinated organics. Four noble metals (Pd, Pt, Ru and $\mathrm{Au}$ ), separately deposited onto the iron surface through a spontaneous redox process, promoted the TCE dechlorination rate, and the catalytic activity of the noble metal followed the order of $\mathrm{Pd} \gg \mathrm{Ru}>\mathrm{Pt}>\mathrm{Au}$. This order was found to be dependent on the concentrations of adsorbed atomic hydrogen, indicating that the initial reaction was cathodically controlled. Little difference in the distribution of the chlorinated products for the four catalysts (cis-DCE: 51\%; 1,1-DCE: 27\%; trans-DCE: 15\% and VC: 7\%) was observed. The chlorinated by-products accumulated in both $\mathrm{Pt} / \mathrm{Fe}$ and $\mathrm{Au} / \mathrm{Fe}(10.3 \%$ and $2.5 \%$ of the transformed TCE, respectively), but did not accumulate in $\mathrm{Pd} / \mathrm{Fe}$ and $\mathrm{Ru} / \mathrm{Fe} . \mathrm{Ru} / \mathrm{Fe}$ was further examined as an economical alternative to $\mathrm{Pd} / \mathrm{Fe}$. The $1.5 \% \mathrm{Ru} / \mathrm{Fe}$ was found to completely degrade TCE within $80 \mathrm{~min}$. Considering the expense, the yield of chlorinated products and the lifetime of a reductive material, Ru provides a potential alternative to Pd as a catalyst in practical applications.

(C) 2004 Elsevier B.V. All rights reserved.
\end{abstract}

Keywords: Bimetallic; Zero-valent metal; Catalytic dechlorination

\section{Introduction}

Destroying aqueous chlorinated organics for environmental remediation requires either high-energy processes (wet oxidation [1]) or complex equipments (ultrasonic technique [2] and photo-catalytic decomposition under UV irradiation [3]). Biological processes may be effective, but conditions must be well controlled to enable microorganisms to grow. In recent years, an efficient and cost-effective method, involving the use of zero-valent metals as reductants to degrade chlorinated organics at room temperature, has been extensively considered to be a promising process for treating industrial wastewater and groundwater [4-8]. Iron, the most commonly used material, is a highly reductive metal for dechlorinating various chlorinated organic compounds, such as chlorinated aliphatics [4,5], chlorinated aromatics [9]

* Corresponding author. Tel.: +886 223625373; fax: +8862 23928821. E-mail address: d89541005@ntu.edu.tw (C.J. Lin). and pesticides [7,8]. Finally, the reactants, including iron and chlorinated organics, are transformed into benign compounds such as hydrocarbons, chlorides and iron oxides.

Several shortcomings, including the accumulation of chlorinated by-products and the decrease in the activity of iron over time, have been noted [6,10-12]. These factors increase the risk associated with the passing of chlorinated products through the treatment system. Improved methods that involve physical and chemical processes include (1) combining ultrasound and iron to accelerate dechlorination reaction and reduce the forming of oxide layers on the surface of iron by continuous cleaning through acoustic cavitation [13]; (2) increasing the surface area of iron by reducing its particle size to enhance the reactivity [10]; and (3) depositing a second metal as a catalyst onto the surface of the iron $[9,11,14-23]$. Of numerous improvement methods tested, the deposition of the second metal as a catalyst onto the surface of iron is considered to be promising, in view of the simplicity of preparation and the rapid and complete dechlorination. 
Earlier studies have used two bimetals systems $[11,16]$. One involves "simple mixing", in which the second metal is added at the same time as the iron particles to the reactors. The other is "complex mixing", in which the second metal is deposited onto the surface of the iron in a redox reaction between the second metal precursor and iron. The former yields slower dechlorination than the latter, because of the effective contact area between iron and the second metal particles is limited.

The deposition of small amounts of the second metal, such as $\mathrm{Pd}, \mathrm{Pt}, \mathrm{Ag}, \mathrm{Ni}$ and $\mathrm{Cu}$ onto iron has been reported in the past 10 years [9,11,14-23]. In all cases, reactions were much faster than those of untreated iron. However, loss of activity of bimetals over time, due to a build up of metal (hydr)oxide film or chemisorption of compounds to active sites or a loss of the loosely bound second metal particles, exhibited the benefit of bimetals to be short-lived. Additionally, leaching of $\mathrm{Ni}$ or $\mathrm{Cu}$ when the iron has been exhausted would be of environmental concern. Platinum group metals such as $\mathrm{Pd}$ are suggested to be a better choice of catalyst for most application because of its chemical stability and high catalytic reactivity. Lowery and Reinhard [24] demonstrated the presence of carbonate species, sulfur species, and chloride in water did not adversely affect Pd catalyst activity, but it may occur for $\mathrm{Ni}$, $\mathrm{Ag}$ and $\mathrm{Cu}$. Due to noble metal's chemical stability, the regeneration of catalyst activity through weakly acid washing or oxidative washing would be obtained without destroying its active sites. However, a loss of recoverable active sites on $\mathrm{Ni}$ was caused through the regeneration process with acid solution [20]. In addition to economic considerations, the impact of any products formed via target pollutant transformation is of vital important for both in situ and above ground treatment system. Production and accumulation of chlorinated products such as dichloroethylene isomers (DCE) and vinyl chloride (VC) in the dechlorination reaction of TCE via zero-valent iron has been observed. They are known to be more toxic than the parent compound. Thus, in addition to increasing the degradation rate of target pollutant, a proper catalyst is implemented to solve the problem of production and accumulation of toxic by-products.

In this work, four noble metals ( $\mathrm{Pd}, \mathrm{Pt}, \mathrm{Ru}$ and $\mathrm{Au})$ were employed to promote the TCE dechlorination rate. The objectives of this work are (1) to compare the activity with TCE of various noble metals ( $\mathrm{Pd}, \mathrm{Pt}, \mathrm{Ru}$ and $\mathrm{Au}$ ) deposited on iron; (2) to identify the production and accumulation of the reaction's chlorinated products during the dechlorination process; and (3) to examined the effect of the nature and loading of the noble metal on the dechlorination rate.

\section{Experimental section}

\subsection{Chemicals}

The chemicals used were trichloroethylene $(99+\%$, Aldrich, Milwaukee, WI), $N$-[2-hydroxyethyl]piperazine- $N N^{\prime}$ - [2-ethanesulfonic acid]acid (HEPES, Sigma) and iron powder (99.6\%, electrolytic and finer than 100 mesh). Additionally, the noble metal precursors, including $\mathrm{PdNO}_{3} \cdot 2 \mathrm{H}_{2} \mathrm{O}$, $\mathrm{H}_{2} \mathrm{PtCl}_{6} \cdot 6 \mathrm{H}_{2} \mathrm{O}, \mathrm{RuCl}_{3}$, and $\mathrm{AuCl}_{3}$, were supplied Alfa. All aqueous solutions were made in water purified with a Milli-Q system $(18.2 \mathrm{M} \Omega / \mathrm{cm})$. The desired concentrations of TCE, $7.5 \mathrm{mg} \mathrm{L}^{-1}$, in Ar-purged water were prepared by dilution of a saturated TCE stock solution, which was made by stirring excess TCE with Ar-purged water. Adding the buffer, $10 \mathrm{mM}$ HEPES, to control the $\mathrm{pH}$ of the solution at the range 7.1-7.3.

\subsection{Bimetals preparation}

Bimetallic particles were prepared by mixing acidic solution of noble metal precursor with iron particles, similar to the previous study $[14,15]$. The deposition of noble metal onto the surface of iron occurred through the following redox reaction.

$\frac{n}{2} \mathrm{Fe}^{0}+\mathrm{M}_{\mathrm{N}}^{n+} \rightarrow \frac{n}{2} \mathrm{Fe}^{2+}+\mathrm{M}_{\mathrm{N}}^{0}$

$\mathrm{M}_{\mathrm{N}}$ is the noble metal and $n$ is valence. Initially, the noble metal precursors were dissolved in the solution of $1 \% \mathrm{HCl}$ at the concentration of $1000 \mathrm{mg} \mathrm{L}^{-1}$. The desired amount of noble metal precursor $\left(0.25,1.0,2.0\right.$ and $2.5 \mathrm{~mL}$ of $1000 \mathrm{mg} \mathrm{L}^{-1}$ of the noble metal), associated to the mass ratio of noble metal to iron $(0.25 \%, 1.0 \%, 2.0 \%$ and $2.5 \%, \mathrm{w} / \mathrm{w})$, was added with stirring to $1 \mathrm{~g}$ of iron particles. Then, the mixture was washed twice by Milli-Q water. The mixture was filtered and then dried via vacuum freeze-drying technique $\left(200 \times 10^{-3}\right.$ Torr and $-56^{\circ} \mathrm{C}$ for $24 \mathrm{~h}$ ).

\subsection{UV/vis spectra}

$\mathrm{UV} /$ vis spectra (GBC, Cintra) were used to understand the redox reaction and confirm the completeness of the redox reaction. First, the aqueous solutions of the noble metal precursor at the concentration of $10 \mathrm{mg} \mathrm{L}^{-1}$ (as noble metal weight) were scanned via the wavelength range of $250-600 \mathrm{~nm}$ to identify the adsorption peaks. After mixing $1 \mathrm{~g}$ of iron particles into the $100 \mathrm{~mL}$ of the noble metal precursor at the concentration of $10 \mathrm{mg} \mathrm{L}^{-1}$, the $2 \mathrm{~mL}$ sample was withdrawn periodically and then filtered through a $0.45 \mu \mathrm{m}$ filter membrane. The filtrate was scanned with the same model of wavelength scan. Comparison of spectra of the original aqueous solution of noble metal precursor with spectra of the filtrate can quantitatively confirm the residual noble metal precursor in the filtrate

\subsection{Characterization of bimetallic particles}

Surface areas were determined by BET $\mathrm{N}_{2}$ adsorption analysis on a Coulter SA3100 surface area analyzer (Coulter Co., Hialeach, FL). The morphology of the resulting bimetallic particles was viewed with Scanning Electron Microscopy (SEM) and localized elemental information from the chose 
region with Energy Disperse X-ray Spectroscopy (EDS) in conjunction with SEM. The oxidation states of noble metals on the surface of iron were identified by electron spectroscopy for chemical analysis (ESCA), a surface-sensitive tool to explore the surface chemistry of bimetallic particles $[25,26]$. The ESCA measurements were perform by using a Vacuum Generators ECSALAB MKП photoelectron spectrometer (East Grinsted, U.K.) with an ALK $\alpha 1,2(1486.6 \mathrm{eV})$ $\mathrm{X}$-ray source and a hemispherical $150 \mathrm{~mm}$ mean radius electron analyzer with a take-off angle of $90^{\circ} \mathrm{C}$. The binding energies of the photoelectrons were determined with the assumption of the carbon $1 \mathrm{~s}$ electrons of $284.5 \mathrm{ev}$. During the data acquisition, the pressure in the sample chamber did not exceed $5 \times 10^{-10}$ Torr. The Tafel polarization curve of the ruthenium aggregate electrode was measured on a potentiostat (Autolab, NL) by scanning the electrode potential at the rate of $0.1 \mathrm{mVs}^{-1}$ from -3 to $3 \mathrm{~V}$. A custom three-electrode cell ( $\mathrm{Ag} / \mathrm{AgCl}$ electrode as a reference electrode) in $1 \mathrm{M} \mathrm{H}_{2} \mathrm{SO}_{4}$ was performed to calculate the exchange current density $\left(i_{0}\right)$. The $i_{0}$ of the ruthenium aggregate electrode, obtained by the intercept of the linear region in the Tafel plot (not shown), was assessed as $10^{-4.8} \mathrm{~A} / \mathrm{cm}^{2}$.

\subsection{Batch experiments}

\subsubsection{Reactor system}

All experiments as function of time were performed with $15 \mathrm{~mL}$ serum bottles. In each bottle, $0.3 \mathrm{~g}$ of bimetallic particles and $10.0( \pm 0.1) \mathrm{mL}$ Ar-purged buffered Milli-Q water were added, leaving a headspace of $5 \mathrm{~mL}$. The vials were capped with Teflon silicone septa and aluminum seals. For the displacement of residual air in the headspace by $\mathrm{He}$ lium, a glass syringe of $20 \mathrm{~mL}$ Helium was injected through the septa and simultaneously an equivalent volume of gas was withdrew by another needle to keep $1 \mathrm{~atm}$. A $100 \mu \mathrm{L}$ aliquot of TCE $(1100 \mathrm{mg} / \mathrm{L})$ was then added through the septa, and mixed on a rotary shaker $(50 \mathrm{rpm})$ at room temperature $\left(25^{\circ} \mathrm{C}\right)$ in the dark.

\subsubsection{Sample analysis}

Gaseous TCE and chlorinated intermediates were measured using a HP5890 GC equipped with a DB-624 capillary column and an electron capture detector operated in the splitless mode. Temperature conditions were programmed as follows: oven temperature at $50^{\circ} \mathrm{C}$; injection port temperature at $280^{\circ} \mathrm{C}$; detector temperature at $300^{\circ} \mathrm{C}$. Ultrapure nitrogen was used as carrier gas for $\mathrm{GC}$ and at a flow rate of $4.16 \mathrm{~mL} / \mathrm{min}$. Gaseous hydrocarbon products were qualitatively identified with HP5890 GC equipped with a HP-1 column and a flame ionization detector. The programmed temperature was as same as the above description. Hydrogen was identified by HP5830 GC with a $180 \mathrm{~cm} \times 0.63 \mathrm{~cm}$ packed molecular sieve no. 5A column and a thermal conductivity detector. Helium was used as the carrier gas at a flow rate of $30 \mathrm{~mL} / \mathrm{min}$. The column temperature was kept at $40^{\circ} \mathrm{C}$. Both the injection and detector temperature were

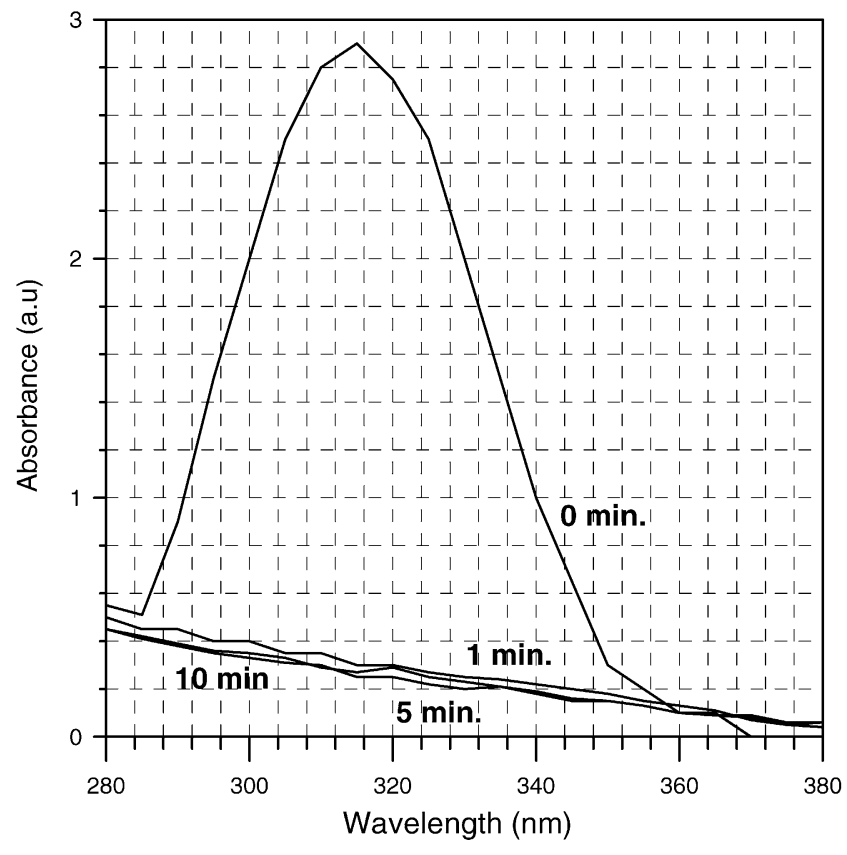

Fig. 1. UV/vis absorption spectra of $\mathrm{Pt}(\mathrm{IV})$ ions in water. The sampled time were $0,1,5$ and 10 min after mixing iron particles with the $\mathrm{H}_{2} \mathrm{PtCl}_{6} \cdot 6 \mathrm{H}_{2} \mathrm{O}$ solution.

$100^{\circ} \mathrm{C}$. Peaks were quantified by comparing retention time and peak areas with standard gas (Supelco).

\section{Results and discussion}

\subsection{Redox reaction between noble metal ions and iron particles}

A color change, orange into pale yellow [15], is commonly used to evaluate the completeness of the reduction of Pd precursor by iron. A large range of reaction times, from a few minutes [15] to several hours [17], has been reported. In this study, UV/vis spectra were used to understand the redox reaction and confirm the completeness of the redox reaction. As Fig. 1 reveals, the absorption peak of the Pt precursor near $315 \mathrm{~nm}$ completely disappeared after mixing iron into the Pt precursor solution for $1 \mathrm{~min}$ (the ratio of $\mathrm{Pt}$ to Fe was at $0.1 \%, \mathrm{w} / \mathrm{w})$. Moreover, both curves, after redox reaction at 5 and $10 \mathrm{~min}$, showed similar absorbance in the region $280-380 \mathrm{~nm}$. Iron very quickly reduced the Pt precursor. The time required to deposit Pt onto an iron surface was less than $1 \mathrm{~min}$. Simultaneously, the absorption peak for $\mathrm{Pd}, \mathrm{Ru}$ and Au precursors were $350-450,425-550$ and $280-380 \mathrm{~nm}$, respectively, and no significant adsorption peak were observed after mixing with iron for $1 \mathrm{~min}$. The UV/vis spectral of the solution during the reduction reaction more precisely indicates the completeness of the reduction, than dose the color change. 
Table 1

The surface area, pseudo-first-order rate constant and average rate of hydrogen evolution for various reductants

\begin{tabular}{lll}
\hline Reductant & BET area $\left(\mathrm{m}^{2} / \mathrm{g}\right)$ & $\begin{array}{c}\text { Constant, } k_{\text {obs }}\left(\mathrm{h}^{-1}\right) \\
\text { Average rate of hydrogen } \\
\text { evolution }{ }^{\mathrm{c}}(\mu \mathrm{mol} / \mathrm{h})\end{array}$ \\
\hline $\mathrm{Pd} / \mathrm{Fe}(0.25 \%, \mathrm{w} / \mathrm{w})$ & $0.91 \pm 0.20$ & $23.3 \pm 4.8$ \\
$\mathrm{Used} \mathrm{Pd} / \mathrm{Fe}^{\mathrm{b}}(0.25 \%, \mathrm{w} / \mathrm{w})$ & $0.93 \pm 0.19$ & 0.65 \\
$\mathrm{Ru} / \mathrm{Fe}(2.0 \%, \mathrm{w} / \mathrm{w})$ & $1.44 \pm 0.30$ & $1.8 \pm 0.31$ \\
$\mathrm{Ru} / \mathrm{Fe}(1.5 \%, \mathrm{w} / \mathrm{w})$ & $1.66 \pm 0.33$ & $2.4 \pm 0.17$ \\
$\mathrm{Ru} / \mathrm{Fe}(1.0 \%, \mathrm{w} / \mathrm{w})$ & $1.16 \pm 0.25$ & $0.435 \pm 0.06$ \\
$\mathrm{Ru} / \mathrm{Fe}(0.25 \%, \mathrm{w} / \mathrm{w})$ & $0.89 \pm 0.18$ & $0.264 \pm 0.007$ \\
Used Ru/Fe $(0.25 \%, \mathrm{w} / \mathrm{w})$ & $0.90 \pm 0.21$ & 0.128 \\
$\mathrm{Pt} / \mathrm{Fe}(0.25 \%, \mathrm{w} / \mathrm{w})$ & $0.84 \pm 0.17$ & $0.041 \pm 0.009$ \\
Au/Fe $(0.25 \%, \mathrm{w} / \mathrm{w})$ & $0.91 \pm 0.20$ & $0.023 \pm 0.009$ \\
Untreated Fe & $0.54 \pm 0.08$ & $0.012 \pm 0.006$ \\
\hline
\end{tabular}

a Errors represent $95 \%$ confidence intervals.

b After continual dipping in Ar-purged Milli-Q water for 10 days.

c Averaged results from replicate tests were reported.

\subsection{Characterizing bimetallic particles}

Several important properties of noble metal/iron particles, including the specific surface area, oxidation states of noble metal and its dispersion on the surface of iron, were analyzed by BET $\mathrm{N}_{2}$ adsorption, ESCA and SEM/EDS mapping, respectively. Initially, various samples, including the bimetallic particles and untreated Fe, were analyzed the surface areas using BET $\mathrm{N}_{2}$ adsorption. The results are listed in Table 1. Depositing noble metals onto the iron surface increased the total surface area as compared to that of the iron, consistent with previous findings [21]. As Table 1 reveals, the total surface areas of $\mathrm{Ru} / \mathrm{Fe}$ particles are determined by the loadings of $\mathrm{Ru}$. The resulting surface area is increased from $0.54 \pm 0.08 \mathrm{~m}^{2} / \mathrm{g}$ of untreated Fe to $1.66 \pm 0.33 \mathrm{~m}^{2} / \mathrm{g}$ of $1.5 \%(\mathrm{w} / \mathrm{w}) \mathrm{Ru} / \mathrm{Fe}$. Initially, the surface area increases with the loading of Ru up to $1.5 \%$. Further increasing in this loading did not continue to increase the total surface area. This result implies that the initial increase in $\mathrm{Ru}$ served to increase the number of fine $\mathrm{Ru}$ particles on the surface of iron. Then, further increasing in $\mathrm{Ru}$ leads to aggregate fine
$\mathrm{Ru}$ particles into large ones and so reduced the total surface area.

The status of noble metal dispersion on the surface of iron highly affects the efficiency of catalytic effects and the homogeneity of bimetallic particles. In this work, the morphology of iron particles after deposition of $\mathrm{Pd}$ was viewed by SEM (Fig. 2(a)). Simultaneously, the distribution of Pd on the surface of iron was exhibited by EDS mapping. As Fig. 2 shows, Pd particles significantly aggregate on certain iron particles (at the central left side of Fig. 2(b)) with moderate non-uniform distribution. The deposition of Pd quickly occurred on the active sites of the iron surface, leading to a highly variability in the magnitude of total surface area compared to the untreated iron with relative standard deviation of $11 \%$ and $7 \%$, respectively (Table 1 ).

When noble metals were deposited onto iron, the oxidation states of noble metals were analyzed by ESCA. As Fig. 3 shows, $\mathrm{Pd}^{0}, \mathrm{Ru}^{0}$ and $\mathrm{Au}^{0}$ are clearly seen in the ESCA spectra, but both $\mathrm{Pt}^{0}$ and $\mathrm{Pt}(\mathrm{II})$ seem to be the dominant oxidation states on the surface of iron. Muftikian et al. [25] postulated the stepwise reduction of $\mathrm{Pd}(\mathrm{IV})$ to $\mathrm{Pd}(\mathrm{II})$, and then to $\mathrm{Pd}^{0}$.
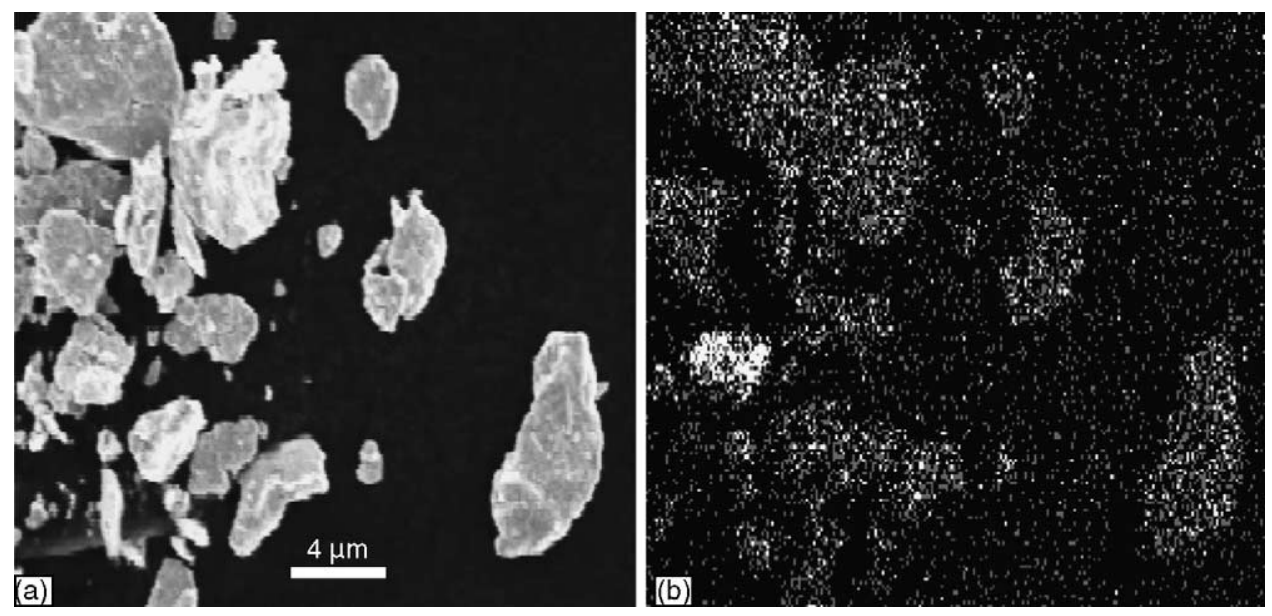

Fig. 2. (a) SEM of Pd/Fe particles (2\%, w/w, magnification $5000 \times$ ). (b) EDX mapping of Pd elements. The spots with high contrast indicated the density of $\mathrm{Pd}$ elements included in $\mathrm{Pd} / \mathrm{Fe}$ particles in Fig. 2a. 

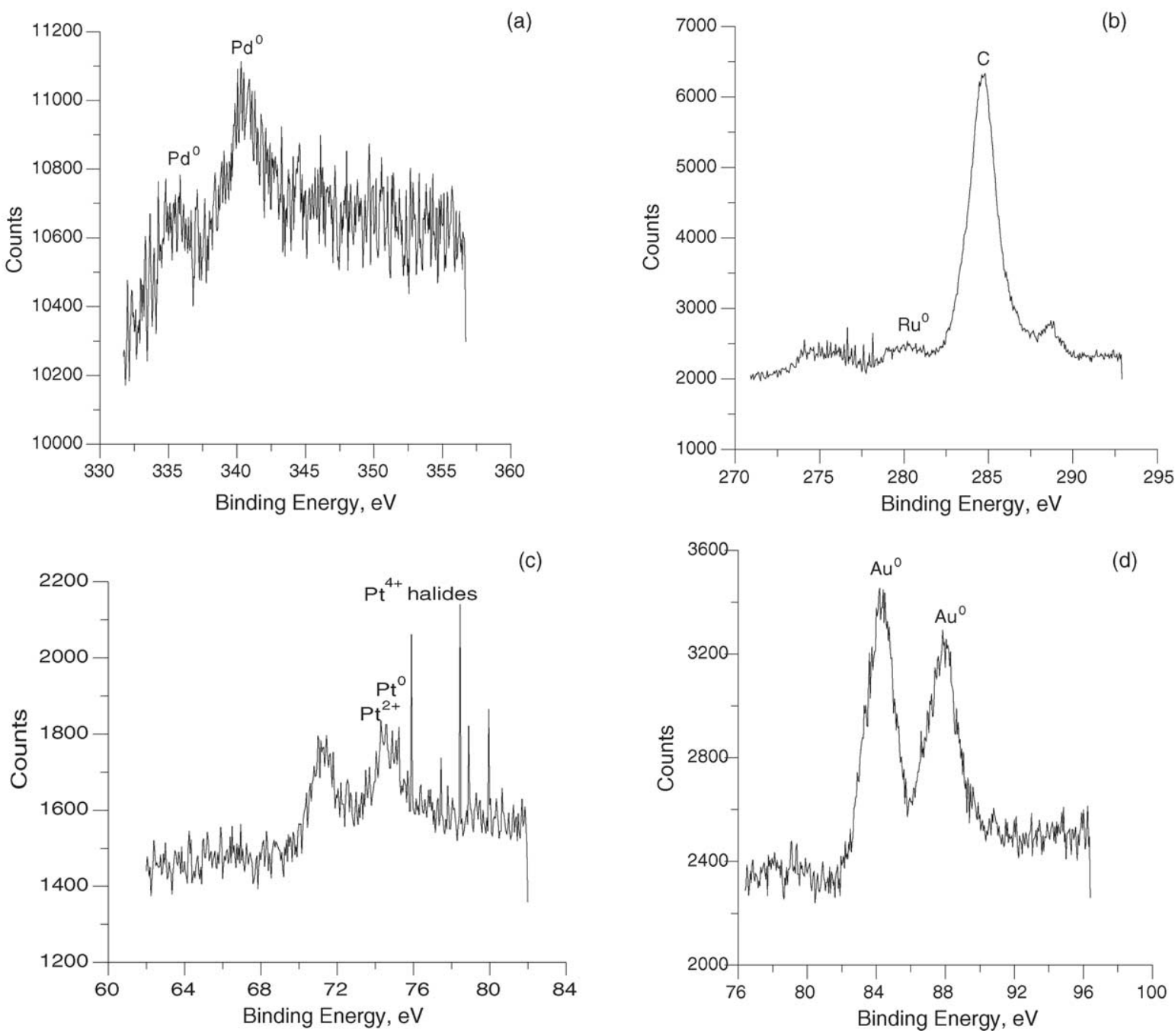

Fig. 3. X-ray photoelectron spectra of Pd, Ru, Pt and Au. (a) Binding energy of the Pd $3 \mathrm{~d}_{5 / 2}$ peaks: $335.1 \mathrm{eV}$. (b) Binding energy of the Ru $3 \mathrm{~d}_{5 / 2}$ peaks: $280.1 \mathrm{eV}$ and C 1s: $284.6 \mathrm{eV}$. (c) Binding energy of the Pt 3f $7 / 2$ peaks: 71.2 eV; Pt 3f $5 / 2$ : $74.5 \mathrm{eV}$; Pt oxides: 73.8-75.0 eV and Pt halides:73.5-77.5 eV. (d) Binding energy of the $\mathrm{Au} 4 \mathrm{f}_{7 / 2}$ peaks: $84.0 \mathrm{eV}$.

Unstable $\mathrm{Pd}(\mathrm{II})-\mathrm{O}-\mathrm{Fe}$ bonds were formed and then collapse spontaneously into the element state. The results from ESCA analysis indicated $\mathrm{Au}(\mathrm{III})$ and $\mathrm{Ru}(\mathrm{III})$ followed the same stepwise reduction of Pd(IV), and zero-valent dominate the oxidation states. However, in a reaction with $\mathrm{Pt}(\mathrm{IV})$ and iron, $\mathrm{Pt}(\mathrm{II})-\mathrm{O}-\mathrm{Fe}$ bonds may be formed more stable than those in $\mathrm{Pd}$ system, leaving the large amount of Pt(II) on the surface of iron.

\subsection{Dechlorination of TCE}

Fig. 4 shows the disappearance rate of $7.5 \mathrm{mg} / \mathrm{L}$ TCE using $0.3 \mathrm{~g}$ of various bimetal particles with $0.25 \%$ noble metal loading, and as a comparison with $1.5 \% \mathrm{Ru} / \mathrm{Fe}$. Obviously, $\mathrm{Pd} / \mathrm{Fe}$ is the most effective in enhancing the activity of iron and complete converted TCE within $5 \mathrm{~min}$. $\mathrm{Ru} / \mathrm{Fe}, \mathrm{Pt} / \mathrm{Fe}$ and $\mathrm{Au} / \mathrm{Fe}$ separately required 6,35 and $110 \mathrm{~h}$ to degrade TCE to the detection limit of the detector, which was $0.005 \mathrm{mg} / \mathrm{L}$. The reaction activity enhanced by noble metals using as catalysts follows the trend $\mathrm{Pd} / \mathrm{Fe} \gg \mathrm{Ru} / \mathrm{Fe}>\mathrm{Pt} / \mathrm{Fe}>\mathrm{Au} / \mathrm{Fe}$. A pseduofirst-order kinetic model was used to evaluate the rate constants $\left(k_{\mathrm{obs}}\right)$, similar to previous researches [4-6]. Table 1 reveals the related values. Of all bimetallic systems, $k_{\text {obs }}$ were increased as compared to untreated iron and the magnitudes of them were $23.3 \pm 4.8,0.264 \pm 0.007,0.041 \pm 0.009$ and $0.023 \pm 0.009 \mathrm{~h}^{-1}$ for $\mathrm{Pd} / \mathrm{Fe}, \mathrm{Ru} / \mathrm{Fe}, \mathrm{Pt} / \mathrm{Fe}$ and $\mathrm{Au} / \mathrm{Fe}$ $(0.25 \%)$, respectively. It may be more practical to normalize $k_{\mathrm{obs}}$ according to the surface area and the mass concentration of bimetal particles as does a monometallic iron system [27]. However, the magnitude of total surface area was provided by two different metal. These values were highly variable as compared to that of monometallic iron (Table 1) due to non-uniform distribution of noble metal on the iron surface. Reaction with bimetallic particles, iron acts as a reductant to transform water into hydrogen on the surface of the noble metal in anaerobic condition; meanwhile the adsorbed intermediate, atomic hydrogen on the noble metal surface, immediately degrades the aqueous or adsorbed TCE $[16,21,23]$. 


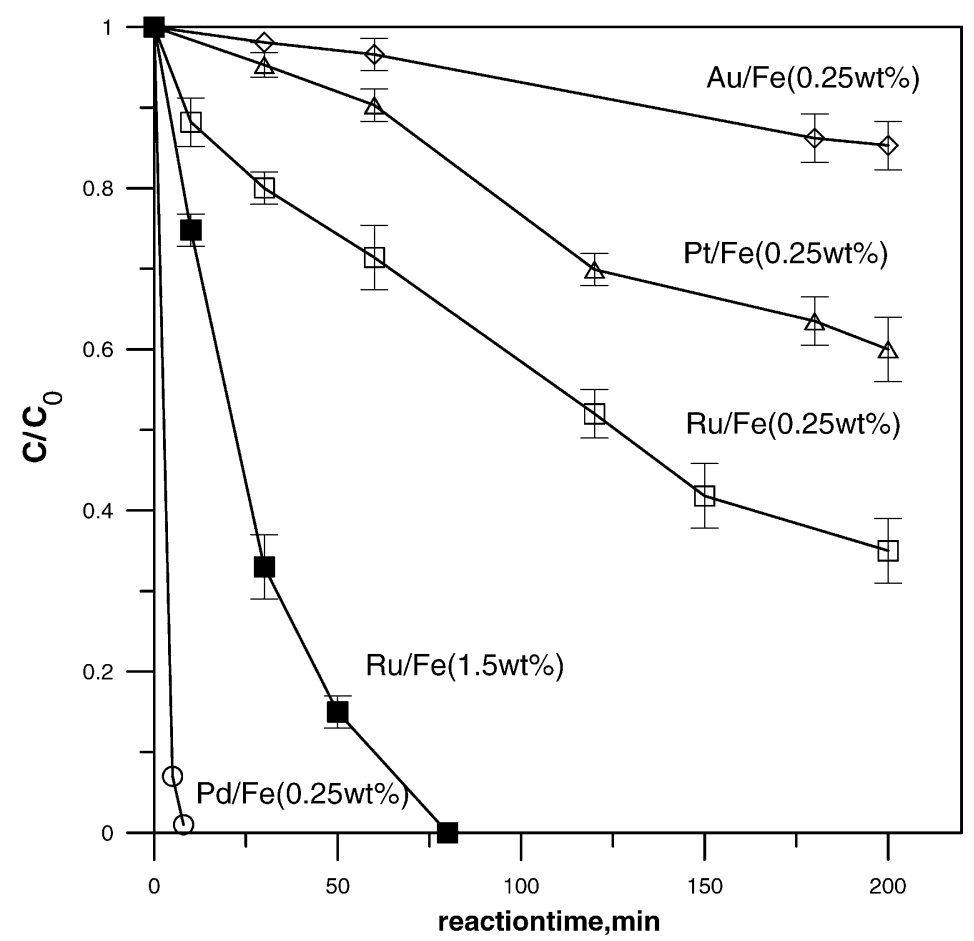

Fig. 4. The disappearance rate of TCE in various bimetallic systems. Errors represent $95 \%$ confidence intervals.

Iron and the noble metal play different roles in the course of the dechlorination reaction. Thus, it is not essential to normalize $k_{\text {obs }}$, unless the individual surface areas of bimetal particles are distinguished.

Previous researches [24,28-30] have indicated hydrogen plays a key role in the dechlorination reaction in the presence of $\mathrm{Pd}$. The concentration of hydrogen in aqueous solution $\left(\left[\mathrm{H}_{2}\right]_{\mathrm{aq}}\right)$ affected the TCE transformation rate and prod- ucts distribution in the $\mathrm{Pd}-\mathrm{on}-\boldsymbol{\gamma}-\mathrm{Al}_{2} \mathrm{O}_{3}$ system [24,30]. The TCE dechlorination rate decreased and the production of chlorinated by-products increased with decreasing $\left[\mathrm{H}_{2}\right]_{\mathrm{aq}}$. In this work, the initial rate of hydrogen generation from $0.3 \mathrm{~g}$ of $\mathrm{Pd} / \mathrm{Fe}, \mathrm{Ru} / \mathrm{Fe}, \mathrm{Pt} / \mathrm{Fe}$ and $\mathrm{Au} / \mathrm{Fe}(0.25 \%)$ in deoxygenated water were evaluated. As Fig. 5 shown, substantial amounts of hydrogen gas were generated in all the four bimetallic systems. No detectable amount of hydrogen was

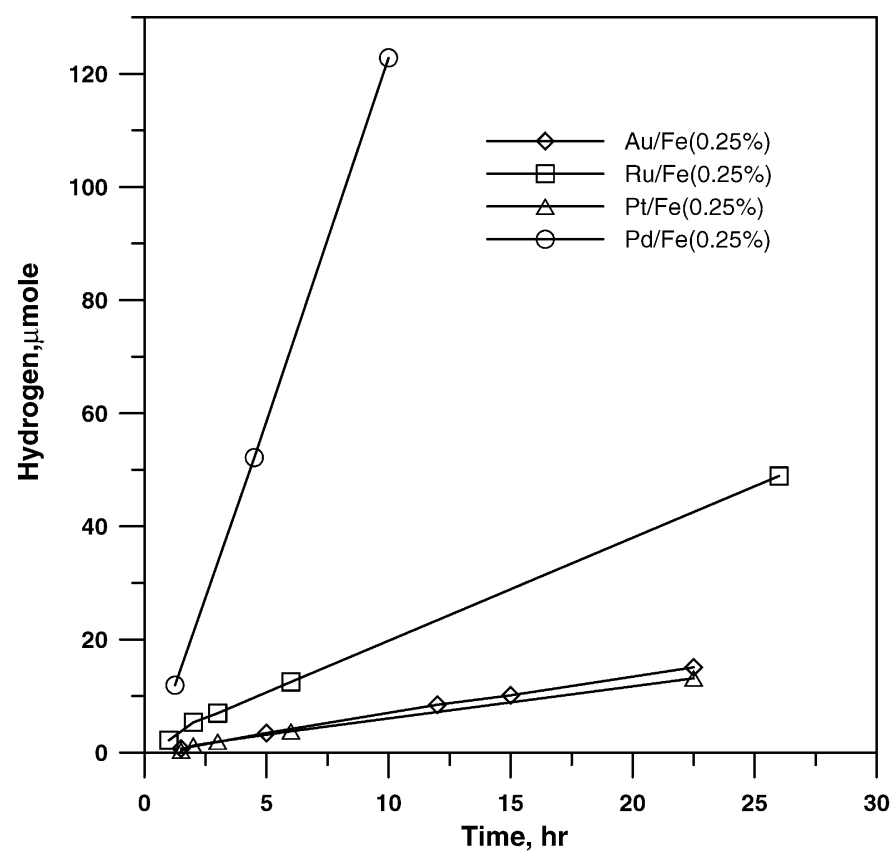

Fig. 5. The initial hydrogen generation in the reaction between $\mathrm{H}_{2} \mathrm{O}$ and various noble metals/iron. 


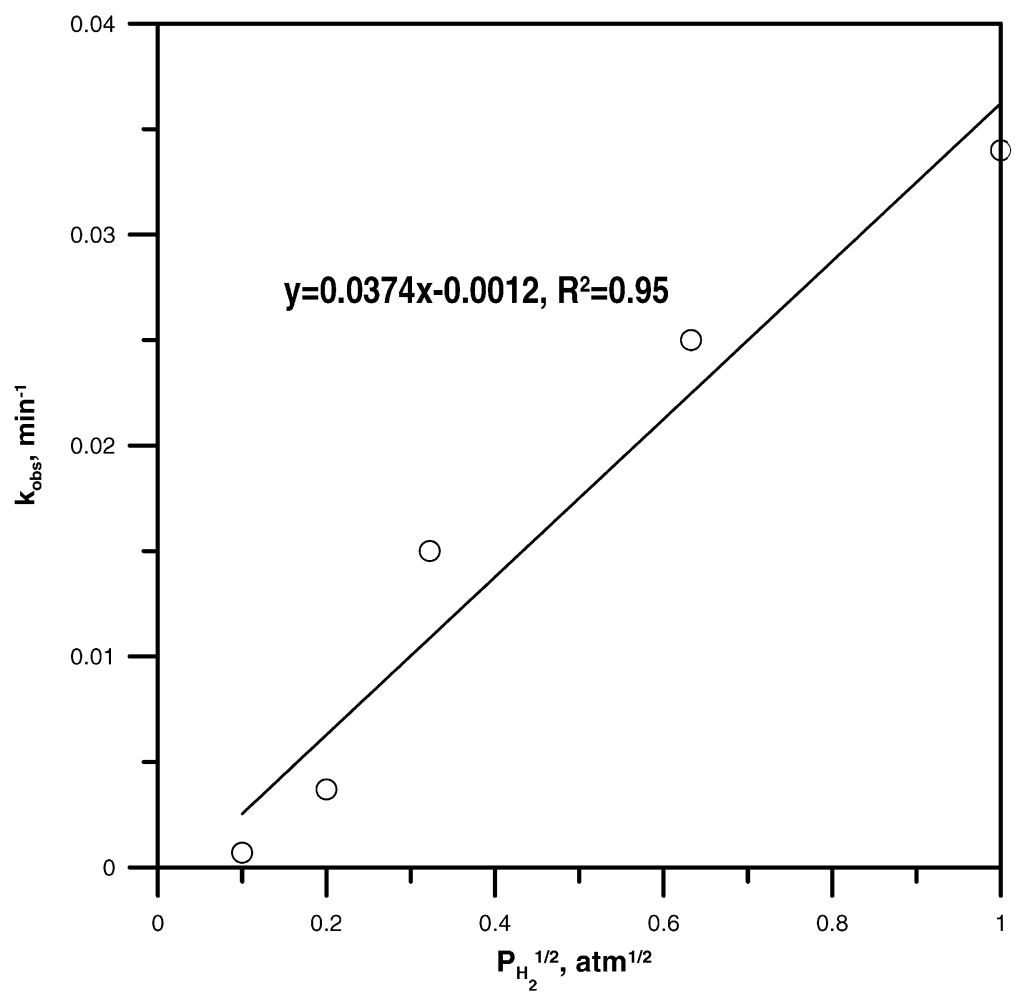

Fig. 6. The relationship between the square root of hydrogen partial pressures and the observed TCE dechlorination rate constants (data were obtained from Lowry and Reinhard's research [30]).

observed in monometallic iron system within $25 \mathrm{~h}$. The average rates of hydrogen evolution were 12.675, 1.868, 0.609 and $0.684 \mu \mathrm{mol} / \mathrm{h}$ for $\mathrm{Pd} / \mathrm{Fe}, \mathrm{Ru} / \mathrm{Fe}, \mathrm{Pt} / \mathrm{Fe}$ and $\mathrm{Au} / \mathrm{Fe}$, respectively (averaged results from duplicate tests were reported). The initial rate for $\mathrm{Pd} / \mathrm{Fe}$ is significant higher than that for $\mathrm{Ru} / \mathrm{Fe}$ or $\mathrm{Pt} / \mathrm{Fe}$ or $\mathrm{Au} / \mathrm{Fe}$. The fact that the better hydrogen generation catalyst gives a higher dechlorination rate seems to be valid. In Table 1, however, the dechlorination rate for TCE using $\mathrm{Au} / \mathrm{Fe}$ was increased two times by $\mathrm{Pt} / \mathrm{Fe}$ with a lower hydrogen evolution rate. Additionally, a highly dechlorination rates were still observed when $\mathrm{Pd} / \mathrm{Fe}$ was continually dipped in Ar-purged Milli-Q water for 10 days without significant amount of hydrogen generated. Thus, the amount of hydrogen evolution is not completely proportional to the dechlorination rate. Adsorbed atomic hydrogen, serving as the reducing agent, has been proposed to contribute to the highly activity of bimetallic particles for organic compounds reduction [20,31]. However, the effect of adsorbed atomic hydrogen on the dechlorination rates has not been established. This research investigated the correlation between the dechlorination rate and the concentration of atomic hydrogen on the surface of noble metal $\left(\left[\mathrm{MH}_{\mathrm{ads}}\right]\right)$. Here, $\left[\mathrm{MH}_{\mathrm{ads}}\right]$ was evaluated via Eqs. (2) and (3) for both hydrogen gas system and electrochemical hydrogen evolution system, respectively [32].

(1) In the hydrogen gas system

$\left[\mathrm{MH}_{\mathrm{ads}}\right]=k P_{\mathrm{H}_{2}}^{1 / 2}$ where $k$ is the rate constant and $P_{\mathrm{H}_{2}}$ is the hydrogen pressure (atm). In this case, $\left[\mathrm{MH}_{\mathrm{ads}}\right]$ is proportional to the square root of the hydrogen pressure. Lowry and Reinhard [30] have reported the observed TCE dechlorination rate constants under various hydrogen partial pressures. Using $P_{\mathrm{H}_{2}}^{1 / 2}$ as $x$-axis and the observed TCE dechlorination rate constants as $y$-axis, a regression line with the coefficient of determination of 0.95 was obtained (Fig. 6). This finding implies that the activity of $\mathrm{Pd}$ as a catalyst to degrade TCE is proportionally increased with $\left[\mathrm{MH}_{\mathrm{ads}}\right]$.

(2) In the electrochemical processes in aqueous solution with noble metal

$\left[\mathrm{MH}_{\mathrm{ads}}\right]=k i$

where $i$ is the cathodic current density $\left(\mathrm{A} / \mathrm{m}^{2}\right)$. In this case, $\left[\mathrm{MH}_{\mathrm{ads}}\right]$ is proportional to the cathodic current density. In this study, bimetallic particles consisting of noble metal and iron with differences of electric potentials are considered to generate hydrogen via electrochemical processes. The exchange current density $\left(i_{0}, \mathrm{~A} / \mathrm{cm}^{2}\right)$, a function of solution, temperature, electrode material, and electrode roughness, is the rate of hydrogen evolution per surface area at the electrode potential, where the reaction is at equilibrium. Exchange current densities differ widely among the different materials. The values of $\mathrm{Pd}, \mathrm{Pt}$ and $\mathrm{Au}$ electrode have been reported at $10^{-3}$, $10^{-3.1}$ and $10^{-5.4} \mathrm{~A} / \mathrm{cm}^{2}$ in $1 \mathrm{M} \mathrm{H}_{2} \mathrm{SO}_{4}$ [33] and that of $\mathrm{Ru}$ was assessed as $10^{-4.8} \mathrm{~A} / \mathrm{cm}^{2}$ via Tafel curve (not shown). 


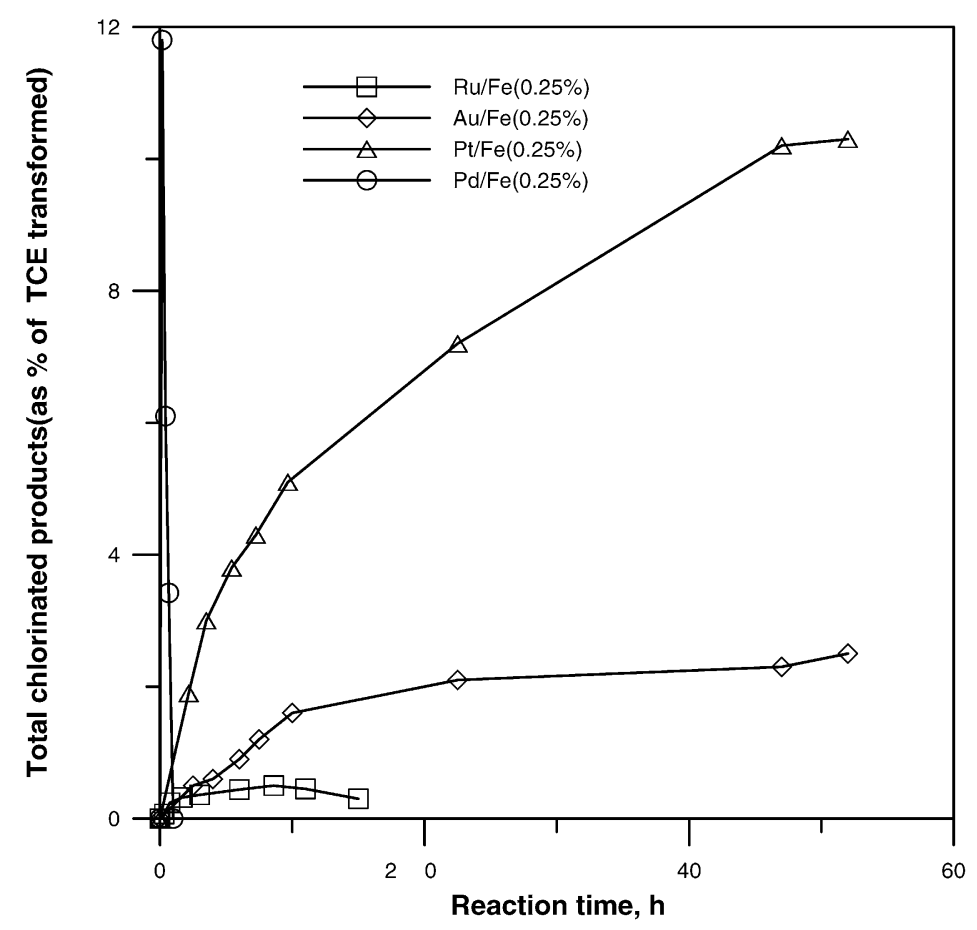

Fig. 7. Concentration profile of total chlorinated products in various bimetallic systems.

A linear relationship between $i_{0}$ of $\mathrm{Au}$ and $\mathrm{Ru}$ and $k_{\mathrm{obs}}$ of $\mathrm{Au} / \mathrm{Fe}$ and $\mathrm{Ru} / \mathrm{Fe}$ was $k_{\mathrm{obs}}=20307 i_{0}-0.0578$. Furthermore, $k_{\text {obs }}$ of $\mathrm{Pt} / \mathrm{Fe}$ and $\mathrm{Pd} / \mathrm{Fe}$ were estimated based on this linear relationship to be 16.1 and $20.2\left(\mathrm{~h}^{-1}\right)$, respectively. In the $\mathrm{Pd} / \mathrm{Fe}$ system, the estimated magnitude of $k_{\mathrm{obs}}$ fell in the interval of $18.5-28.1\left(\mathrm{~h}^{-1}\right)$ with $95 \%$ confidence. However, the states of the Pt surface dominated by both $\mathrm{Pt}^{0}$ and $\mathrm{Pt}(\mathrm{II})$ (Fig. 3) caused a large difference between the estimated and experimental values. Thus, the initial dechlorination rate primarily depends on the concentration of adsorbed atomic hydrogen on the surface of the second metal and is cathodically controlled.

\subsection{Reduction products from noble metal/iron}

Heterogeneous reactions between aqueous chlorinated organics and bimetallic particles require the reactant to move close to the surface of the solid and then be chemisorbed at reactive sites. After a chemical reaction at these sites, the products are desorbed into the solution. In the above processes, the catalyst is important in selectively adsorbing the reactants and desorbing the products according to its affinity for them. As Fig. 7 shows, total chlorinated products, including VC, 1,1-DCE, trans-DCE and cis-DCE, are produced at different yield for the four catalysts in the course of the reaction. Total chlorination products accounts for $11.8 \%, 0.5 \%$, $10.3 \%$ and $2.5 \%$ of TCE transformed at the maximum for $\mathrm{Pd} / \mathrm{Fe}, \mathrm{Ru} / \mathrm{Fe}, \mathrm{Pt} / \mathrm{Fe}$ and $\mathrm{Au} / \mathrm{Fe}$, respectively. Little difference in the distribution of chlorinated products for the four catalysts (cis-DCE: 51\%; 1,1-DCE: 27\%; trans-DCE: $15 \%$ and VC: $7 \%$ ) was observed. Replicate experiments indicated the distribution of chlorinated products were reproducible within 5-10\%. No accumulation of chlorinated products was observed in $\mathrm{Pd} / \mathrm{Fe}$ and $\mathrm{Ru} / \mathrm{Fe}$ systems, due to the their high dechlorination activity. However, the amount of chlorinated products achieved the maximum when TCE completely degraded, and persisted in the $\mathrm{Pt} / \mathrm{Fe}$ and $\mathrm{Au} / \mathrm{Fe}$ systems. This indicates that $\mathrm{Pd}$ or $\mathrm{Ru}$ as a catalyst not only rapidly destroys TCE, target pollutant, but also completely transforms chlorinated products into hydrocarbons. Carbon mass balances of more than $90 \%$ relative to the spiked TCE were obtained. Chlorine after the complete TCE degradation was in good agreement with theoretical ones ( $>95 \%$ accountability). Replicate experiments indicated that carbon and chlorine balance were reproducible within 5-10\%. Although, the dechlorination rates are promoted by $\mathrm{Pt}$ and $\mathrm{Au}$, these systems with residual chlorinated products are impractical. Finally, ethane predominated the hydrocarbon products in $\mathrm{Pd} / \mathrm{Fe}, \mathrm{Ru} / \mathrm{Fe}$ and $\mathrm{Pt} / \mathrm{Fe}$ systems, but ethane and ethene in a ratio of 1:1 was observed in $\mathrm{Au} / \mathrm{Fe}$ system. These observation results were explained by the fact that TCE may undergo hydrogenolysis and hydrogenation of the double bond to form ethane in $\mathrm{Pd} / \mathrm{Fe}, \mathrm{Ru} / \mathrm{Fe}$ and $\mathrm{Pt} / \mathrm{Fe}$ systems. However, ethene, the first hydrocarbon product, easily desorbs from the Au surface into water because of its relatively weak adsorption bond, and then releases into the gas phase. The nature of $\mathrm{Au}$ differs from $\mathrm{Pd}, \mathrm{Pt}$ and $\mathrm{Ru}$, leading to ethane and ethene in a ratio of 1:1 being observed in the $\mathrm{Au} / \mathrm{Fe}$ system, rather than only ethane predominating the hydrocarbon products. 
Depositing noble metal onto iron surface, electrically connecting two dissimilar metals, gives a driving force to accelerate the corrosion of iron, known as galvanic corrosion. In anaerobic and weakly acidic solution, the anodic reaction is given by

$\mathrm{Fe} \rightarrow \mathrm{Fe}^{2+}+2 \mathrm{e}^{-}$

while, the cathodic reactions are expressed as

$$
\begin{aligned}
& \mathrm{H}^{+}+\mathrm{e}^{-}+\mathrm{M}_{\mathrm{N}} \leftrightarrow \mathrm{M}_{\mathrm{N}} \mathrm{H}_{\mathrm{ads}} \\
& \mathrm{M}_{\mathrm{N}} \mathrm{H}_{\mathrm{ads}}+\mathrm{M}_{\mathrm{N}} \mathrm{H}_{\mathrm{ads}} \rightarrow \mathrm{H}_{2}+\mathrm{M}_{\mathrm{N}}
\end{aligned}
$$

The measurement of the amount of products generation or reactants loss is a convenient method for determining the rate of galvanic corrosion [34]. In this study, the measurement of hydrogen generation is preferred over weight loss measurement due to possible errors in iron oxides precipitation. The initial hydrogen generation rate follows the trend $\mathrm{Pd} / \mathrm{Fe}>\mathrm{Ru} / \mathrm{Fe}>\mathrm{Au} / \mathrm{Fe}>\mathrm{Pt} / \mathrm{Fe}(12.675,1.868,0.684$ and $0.609 \mu \mathrm{mol} / \mathrm{h}$, respectively). The result indicated that the initial corrosion rate of $\mathrm{Pd} / \mathrm{Fe}$ was faster by a factor of 7 and 11 as compared to $\mathrm{Ru} / \mathrm{Fe}$ and $\mathrm{Au} / \mathrm{Fe}$, respectively. The value of $i_{0}$ of the noble metal significantly affects the initial corrosion rate [35]. Initially, a high $i_{0}$ of Pd (the cathode) would quickly corrode the iron (the anode) resulting in a buildup of oxides layers. Then, this reaction was shifted to anodic control, eventually halting further corrosion. Experimental evidence demonstrated that the initial hydrogen generation rates were at 12.675 and $1.868 \mu \mathrm{mol} / \mathrm{h}$ for $\mathrm{Pd} / \mathrm{Fe}$ and $\mathrm{Ru} / \mathrm{Fe}(0.25 \%)$, respectively. However, a slower rate at $0.042 \mu \mathrm{mol} / \mathrm{h}$ for $\mathrm{Pd} / \mathrm{Fe}$ than at $0.821 \mu \mathrm{mol} / \mathrm{h}$ for $\mathrm{Ru} / \mathrm{Fe}$ was observed after continual dipping in Ar-purged Milli-Q water for 10 days. Thus, the advantage of $\mathrm{Pd} / \mathrm{Fe}$ compared to other bimetallic particles tested in this work would be shortlived.

Experiments with various loadings of Ru were performed. As Table 1 shows, the observed rate constants increase with the mass ratio of $\mathrm{Ru}$ to $\mathrm{Fe}$ from 0.25 to $1.5 \%$ (from $0.246 \pm 0.007$ to $2.4 \pm 0.17 \mathrm{~h}^{-1}$ ). Further increasing this ratio did not continue to increase the rate constant. Reaction with $1.5 \% \mathrm{Ru} / \mathrm{Fe}$, a complete degradation of TCE was achieved within $80 \mathrm{~min}$. The price of $\mathrm{Ru}$ particles is approximately $10 \%$ of that of Pd particles (Alfa). Thus, considering their expense, the chlorinated products yield and the lifetime of a reductive material, $\mathrm{Ru}$, is a potential alternative to $\mathrm{Pd}$ as a catalyst in practical applications. However, further compared experiments are needed to investigate the catalyst poisoning, particularly in solutions containing $\mathrm{SO}_{3}{ }^{2-}$ and $\mathrm{HS}^{-}$cause rapid Pd deactivation [24].

\section{Conclusions}

Four noble metals (Pd, $\mathrm{Pt}, \mathrm{Ru}$ and $\mathrm{Au})$ used as catalysts effectively enhanced the dechlorination of TCE by iron. The results obtained in this study have demonstrated the following:

(1) Depositing noble metals onto the iron surface, a spontaneous redox reaction, was evaluated by UV/vis spectra to complete less than $1 \mathrm{~min}$. The oxidation states of various noble metals on the surface of iron detected by ESCA revealed $\mathrm{Pd}^{0}, \mathrm{Ru}^{0}$ and $\mathrm{Au}^{0}$ were predominant on the surface of iron, but $\mathrm{Pt}^{0}$ and $\mathrm{Pt}(\mathrm{II})$, even $\mathrm{Pt}(\mathrm{IV})$, were detected on the surface of iron.

(2) Reactions with $\mathrm{Pd} / \mathrm{Fe}$ and $\mathrm{Ru} / \mathrm{Fe}$ separately produced total chlorinated products at $11.8 \%$ and $0.5 \%$ of the transformed TCE at the maximum, but disappeared thereafter. In contrary, total chlorinated products accumulated in $\mathrm{Pt} / \mathrm{Fe}$ and $\mathrm{Au} / \mathrm{Fe}$ systems with the maximum yield of $10.3 \%$ and $2.5 \%$, respectively. Finally, ethane predominated the hydrocarbon products in $\mathrm{Pd} / \mathrm{Fe}, \mathrm{Ru} / \mathrm{Fe}$ and $\mathrm{Pt} / \mathrm{Fe}$ systems, but ethane and ethene in a ratio of $1: 1$ was observed in $\mathrm{Au} / \mathrm{Fe}$ system.

(3) Increasing the mass ratio of $\mathrm{Ru}$ and Fe to $1.5 \%$, a complete dechlorination was achieved less than $80 \mathrm{~min}$. Simultaneously, a slower corrosion reaction was observed in $\mathrm{Ru} / \mathrm{Fe}$ system as compared to $\mathrm{Pd} / \mathrm{Fe}$ system. Thus, considering the expense, the chlorinated products yield and the lifetime of a reductive material, $\mathrm{Ru}$, is a potential alternative to $\mathrm{Pd}$ as a catalyst in practical applications.

(4) The concentrations of adsorbed atomic hydrogen, dependent on the exchange current density of the noble metal, determined the dechlorination rate, indicating the initial reaction was cathodically controlled.

\section{Acknowledgement}

The authors would like to thank the National Science Council of the Republic of China for financially supporting this research under Contract no. NSC 92-2211-E-002-063.

\section{References}

[1] J. Qin, Q. Zhang, K.T. Chuang, Catalytic wet oxidation of $p$ chlorophenol over supported noble metal catalysts, Appl. Catal. B29 (2001) 115-123.

[2] D. Drijvers, H. van Langenhove, L.N.T. Kim, L. Bray, Sonolysis of an aqueous mixture of trichloroethylene and chlorobenzene, Ultroson. Sonochem. 6 (1999) 115-121.

[3] S. Yamazaki, S. Matsunaga, K. Hori, Photocatalytic degradation of trichloroethlyene in water using $\mathrm{TiO}_{2}$ pellets, Water Res. 35 (2001) 1022-1028.

[4] R.W. Gillham, S.F. O'Hannesin, Enhanced degradation of halogenated aliphatics by zero-valent iron, Ground Water 32 (1994) 958-967.

[5] L.J. Matheson, P.G. Tratnydk, Reductive dehalogenation of chlorinated methanes by iron metal, Environ. Sci. Technol. 28 (1994) 2045-2053.

[6] W.S. Orth, R.W. Gillham, Dechlorination of trichloroethene in aqueous solution using $\mathrm{Fe}^{0}$, Environ. Sci. Technol. 30 (1996) 66-71.

[7] A. Agrawal, P.G. Tratnyek, Reduction of nitro aromatic compounds by zero-valent iron metal, Environ. Sci. Technol 30 (1996) 153-160. 
[8] G.D. Sayles, G. You, M. Wang, M.J. Kupferle, DDT, DDD, and DDE dechlorination by zero-valent iron, Environ. Sci. Technol. 31 (1997) 3448-3454.

[9] Y.H. Kim, E.R. Carraway, Dechlorination of pentachlorophenol by zero valent iron and modified zero valent irons, Environ. Sci. Technol. 34 (2000) 2014-2017.

[10] C.B. Wang, W.X. Zhang, Synthesizing nanoscale iron particles for rapid and complete dechlorination of TCE and PCBs, Environ. Sci. Technol. 31 (1997) 2154-2156.

[11] S.F. Cheng, S.C. Wu, The enhancement methods for the degradation of TCE by zero-valent metals, Chemosphere 41 (2000) 1263-1270.

[12] R.A. Doong, K.T. Chen, H.C. Tasi, Reductive dechlorination of carbon tetrachloride and tetrachloroethylene by zerovalent silicon-iron reductants, Environ. Sci. Technol. 37 (2003) 2575-2581.

[13] H.M. Hung, M.R. Hoffmann, Kinetics and mechanism of the enhanced reductive degradation of $\mathrm{CCl}_{4}$ by elemental iron in the presence of ultrasound, Environ. Sci. Technol. 32 (1998) 3011-3016.

[14] R. Muftikian, Q. Fernando, N. Korte, A method for rapid dechlorination of low molecular weight chlorinated hydrocarbons in water, Water Res. 29 (1995) 2434-2439.

[15] C. Grittini, M. Malcomson, Q. Fernando, N. Korte, Rapid dechlorination of polychlorinated biphenyls on the surface of a $\mathrm{Pd} / \mathrm{Fe}$ bimetallic system, Environ. Sci. Technol. 29 (1995) 2898-2900.

[16] I.F. Cheng, Q. Fernando, N. Korte, Electrochemical dechlorination of 4-chlorophenol to phenol, Environ. Sci. Technol. 31 (1997) 1074-1078.

[17] W.X. Zhang, C.B. Wang, H.L. Lien, Treatment of chlorinated organic contaminants with nanoscale bimetallic particles, Catal. Today 40 (1998) 387-395.

[18] J.P. Fennelly, A.L. Roberts, Reaction of 1,1,1-trichloroethane with zero-valent metals and bimetallic reductants, Environ. Sci. Technol. 32 (1998) 1980-1988.

[19] W. Li, K.J. Klabunde, Ultrafine zinc and nickel, palladium, silver coated zinc particles used for reductive dechlorination of chlorinated ethylenes in aqueous solution, Croat. Chem. Acta 71 (1998) $853-872$.

[20] L. Gui, R.W. Gillham, M.S. Odziemkowski, Reduction of $N$ nitrosodimethylamine with granular iron and nickel-enhanced iron. 1. Pathways and kinetics, Environ. Sci. Technol. 34 (2000) 3489-3494.

[21] Y. Liu, F. Yang, P.L. Yue, G. Chen, Catalytic dechlorination of chlorophenols in water by palladium/iron, Water Res. 35 (2001) $1887-1890$
[22] J. Morales, R. Hutcheson, I.F. Cheng, Dechlorination of chlorinated phenols by catalyzed and uncatalyzed $\mathrm{Fe}(0)$ and $\mathrm{Mg}(0)$ particles, $\mathrm{J}$. Hazard. Mater. B90 (2002) 97-108.

[23] B. Schrick, J.L. Blough, A.D. Jones, T.E. Mallouk, Hydrodechlorination of trichloroethylene to hydrocarbons using bimetallic nickel-iron nanoparticles, Chem. Mater. 14 (2002) 5140-5147.

[24] G.V. Lowry, M. Reinhard, Pd-catalyzed TCE dechlorination in groundwater: solute effects, biological control, and oxidative catalyst regeneration, Environ. Sci. Technol. 34 (2000) 32173223.

[25] R. Muftikian, K. Nebesny, Q. Fernando, N. Korte, X-ray photoelectron spectra of the palladium-iron bimetallic surface used for the rapid dechlorination of chlorinated organic environmental contaminants, Environ. Sci. Technol. 30 (1996) 3593-3596.

[26] N. Ruiz, S. Seal, D. Reinhart, Surface chemical reactivity in selected zero-valent iron samoles used in groundwater remediation, J. Hazard. Mater. B80 (2000) 107-117.

[27] T.L. Johnson, M.M. Scherer, P.G. Tratnyek, Kinetics of halogenated organic compound degradation by iron metal, Environ. Sci. Technol. 30 (1996) 2634-2640.

[28] C.G. Schreier, M. Reinhard, Catalytic hydrodehalogenation of chlorinated ethylenes using palladium and hydrogen for the treatment of contaminated water, Chemosphere 31 (1995) 34753487.

[29] W.W. McNab, R. Ruiz, Palladium-catalyzed reductive dehalogenation of dissolved chlorinated aliphatics using electrolyticallygenerated hydrogen, Chemosphere 37 (1998) 925-936.

[30] G.V. Lowry, M. Reinhard, Pd-catalyzed TCE dechlorination in water: effect of $\left[\mathrm{H}_{2}\right](\mathrm{aq})$ and $\mathrm{H} 2$-utilizing competitive solutes on the TCE dechlorination rate and product distribution, Environ. Sci. Technol. 35 (2001) 696-702.

[31] J. Wang, P. Blowers, J. Farrell, Understanding reduction of carbon tetrachloride at nickel surfaces, Environ. Sci. Technol. 38 (2004) 1576-1581.

[32] T.P. Perng, J.K. Wu, A brief review note on mechanisms of hydrogen entry into metals, Mater. Lett. 57 (2003) 3437-3438.

[33] J.O'M. Bockris, A.K.N. Reddy, Modern Electrochemistry, vol. 2, Plenum Press, New York, 1973, p. 1238.

[34] G.O. Davis, J. Kolts, N. Sridhar, Polarization effects in galvanic corrosion, Corrosion 42 (1986) 329-336.

[35] D.A. Jones, Principles and Prevention of Corrosion, second ed., Prentice-Hall, New Jersey, 1996, p. 174. 